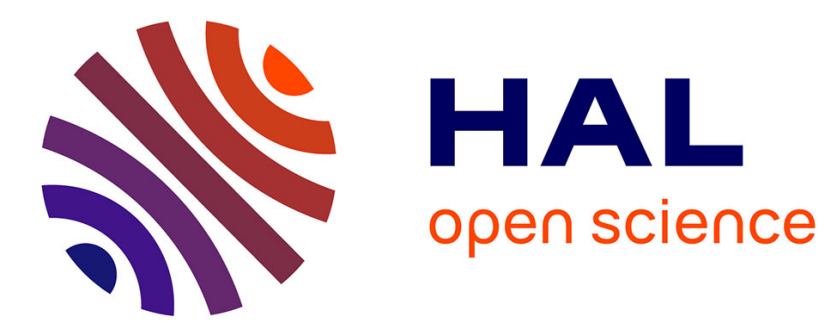

\title{
Hyperspectral Vegetation Indices Calculated by Qgis Using Landsat Tm Image: a Case Study of Northern Iceland
}

\author{
Polina Lemenkova
}

\section{To cite this version:}

Polina Lemenkova. Hyperspectral Vegetation Indices Calculated by Qgis Using Landsat Tm Image: a Case Study of Northern Iceland. Advanced Research in Life Sciences, 2020, 4 (1), pp.70-78. 10.2478/arls-2020-0021 . hal-03030414

\section{HAL Id: hal-03030414 https://hal.science/hal-03030414}

Submitted on 30 Nov 2020

HAL is a multi-disciplinary open access archive for the deposit and dissemination of scientific research documents, whether they are published or not. The documents may come from teaching and research institutions in France or abroad, or from public or private research centers.
L'archive ouverte pluridisciplinaire HAL, est destinée au dépôt et à la diffusion de documents scientifiques de niveau recherche, publiés ou non, émanant des établissements d'enseignement et de recherche français ou étrangers, des laboratoires publics ou privés. 
$\underline{\text { www.degruyter.com/view/j/arls }}$

\title{
Hyperspectral Vegetation Indices Calculated by Qgis Using Landsat Tm Image: a Case Study of Northern Iceland
}

\author{
Polina Lemenkova \\ Schmidt Institute of Physics of the Earth, Russian Academy of Sciences. Department of Natural \\ Disasters, Anthropogenic Hazards and Seismicity of the Earth. Laboratory of Regional \\ Geophysics and Natural Disasters (Nr. 303). Bolshaya Gruzinskaya St, 10, Bld. 1, Moscow, \\ 123995, Russian Federation
}

Received September, 2020; Revised November, 2020; Accepted November, 2020

\begin{abstract}
The vegetation indices (VIs) derived from the hyperspectral reflectance of vegetation are presented in this study for monitoring live green vegetation in the northern ecosystems of Iceland, along the fjords of Eyjafjörður and the Skagafjörður. The comparative analysis of the following VIs was performed: the NDVI, RVI, NRVI, TVI, CTVI, TTVI and SAVI. The methodology is based on the raster calculator band in a QGIS. The dataset includes a Landsat TM scene of 2013, UTM Zone 53, WGS84 captured from the GloVis. The computed bands include the NIR and R spectral bands and their combinations according to the algorithms of each of the seven VIs. The hyperspectral reflectance and crop canopy computations were applied to generate various scales of VIs and demonstrated following data range: NDVI: -0.91 to 0.65 , RVI: 0.22 to 19.65 , NRVI: 0.63 to 0.90 , TVI: 0 to 1.12 , CTVI: -0.64 to 1.07 , TTVI: 0.70 to 1.18 and SAVI: -1.36 to 0.99 (roughly to 1.00). Of these, the RVI, NRVI, TVI and TTVI are adjusted to the positive values while the NDVI, CTVI and SAVI do include the negative diapason in the dataset due to the computing algorithm. The algorithms of the seven VIs are described and visualized in form of maps based on the multispectral remote sensing Landsat TM imagery identifying vegetated areas, their health condition and distribution of green areas against the bare soils, rocks, ocean water, lakes and ice-covered glaciers. The paper contributes both to the technical presentation of the QGIS functionality for the Landsat TM data processing by a raster calculator, and to the regional geographic studies of Iceland and Arctic ecosystems.
\end{abstract}

Keywords: Landsat TM, QGIS, NDVI, Vegetation Index, Cartography

\section{Introduction}

Recently, due to the rapid development of remote sensing techniques and GIS, various methods are developed and presented as applications of the satellite image processing. The methods of calculations of the Vegetation Indices (VIs) applied for various types of landscapes have become popular for vegetation studies and analysis of the biophysical variables in forests and agricultural crop types. The functional principle of the VIs specifically in Landsat TM image consists

\footnotetext{
* Corresponding author: Polina Lemenkova, pauline.lemenkova@gmail.com

(cc)) BY-No-ND $(2020$ P. Lemenkova., published by De Gruyter Open. This work was licensed under the Creative Commons Attribution-NonCommercialNoDerivs 3.0 License
}

in selecting certain combinations bands showing a surface reflectance at the two or more spectral wavelengths. Applying such a combination or adding a mathematical formula enables to highlight a particular property of vegetation.

Each of the VIs has its specifics depending on the cartographic approach and on which particular vegetation property is designed to be highlighted (e.g. pigments, water, carbon, chlorophyll, nutrients). However, all methods of combination of the Landsat TM bands are based on the reflectance properties of vegetation. The Landsat TM includes seven spectral bands, which consists of the multispectral and a thermal band. With the exception of Band 6 (thermal diapason with $120 \mathrm{~m}$ resolution), all other Landsat TM bands have 30 meters resolution. Among the Landsat TM 
spectral bands, the Bands 1-3 correspond to the visible part of spectrum: diapasons $0.45-0.52 \mu \mathrm{m}$, $0.52-0.60 \mu \mathrm{m}$ and $0.63-0.69 \mu \mathrm{m}$ for the Bands 1 , 2 and 3 , respectively. Bands 4 and 5 cover the
Near-Infrared (0.76-0.90 $\mu \mathrm{m}$ and 1.55-1.75 $\mu \mathrm{m})$ part of the spectrum. The Band 6 is a thermal spectral interval $(10.40-12.50 \mu \mathrm{m})$, and Band 7 is a Mid-Infrared (2.08-2.35 $\mu \mathrm{m})$.

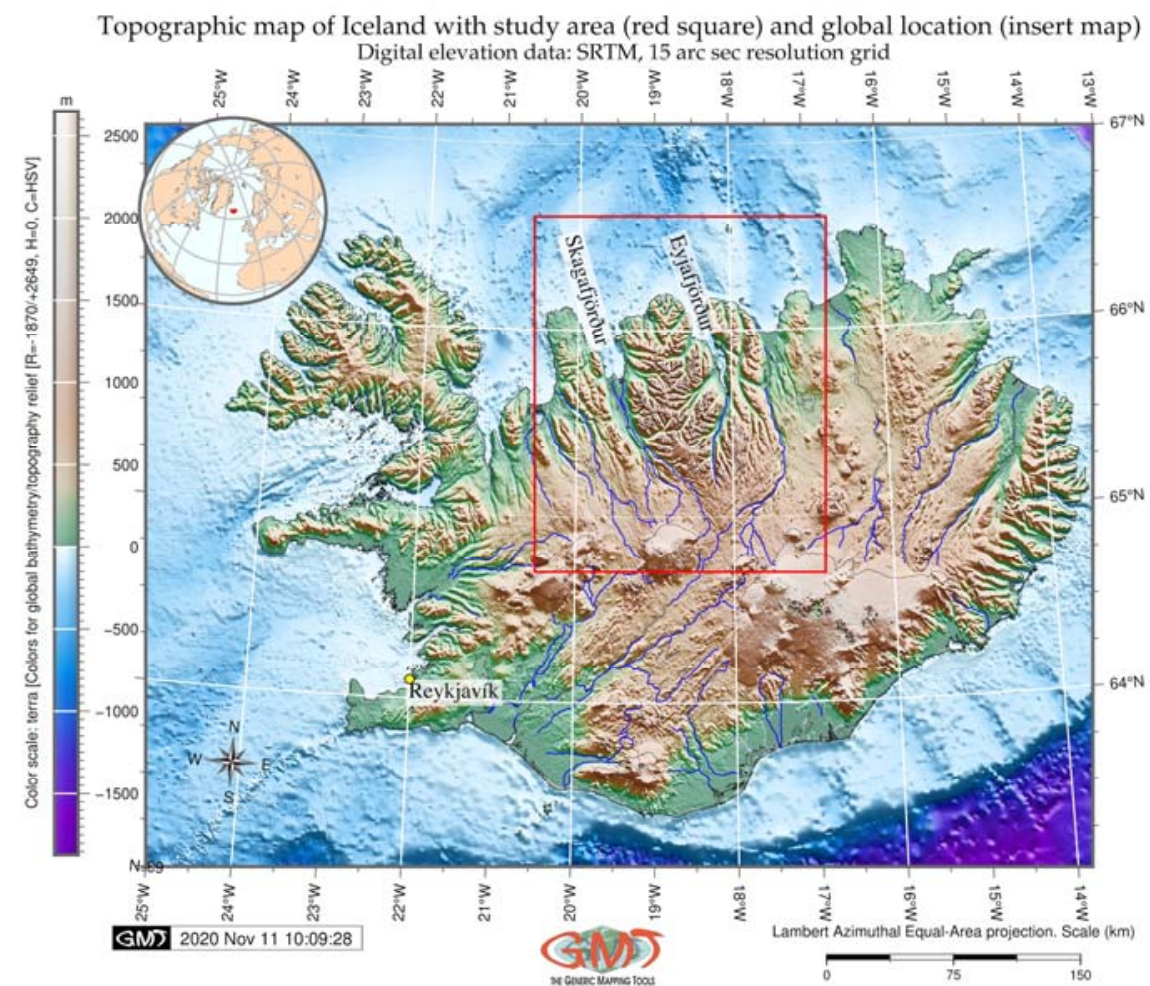

Figure 1. Topographic map of the study area. Mapping: GMT. Source: author.

For the vegetation studies, the most useful and applicable bands include Near-Infrared (NIR) and visible part of the spectrum (especially, Red band), because of the specific vegetation property of leaves that has a distinct spectral reflectance in the red part of the spectrum. In addition to the theoretical principle of the spectral reflectance of vegetation, a practical availability of the QGIS as an open source software [1] together with the Landsat TM free datasets enable an application of the remote sensing data processing for studying of spectral reflectance of vegetation. The advantages of the Landsat TM satellite imagery consist in following technical characteristics: 1) 30-m resolution which provides the required accuracy; 2) the availability of various spectral bands, which makes possible calculating the VIs using their combination; 3) the geographic global coverage; 4) GeoTIFF raster data format readable by all major GIS software including the QGIS. As a result, there is a variety of publications on calculating the VIs in general and the NDVI in particular [2-7], which have been considered in this study as a methodological background.

The geographic extent of the study area covers the northern coasts of Iceland, along the fjords of
Eyjafjörður and Skagafjörður (Figure 1). Located in a severe Arctic climate, this region experienced the effects of the climate changes [8], the dynamics of the permafrost [9] and the shelf ice movement [10]. Active livestock grazing reflected in the land use affects vulnerable Arctic ecosystems through the eroded and degraded lands [11-14]. The geological and glacial processes, such as ablation and volcanism additionally contribute to the soil erosion in the study area and affect vegetation, as recently reported in several studies published on the Iceland land cover mapping. Among the recorded vegetation species in Iceland one should mention beech (Fagus sp.), downy birch (Betula pubescens), rowan (Sorbus aucuparia), aspen (Populus tremula), tea-leaved willow shrub (Salix phylicifolia) and some conifers. The vegetation species in Iceland mostly grow scarce and as shrubs reaching a maximum of ca. $15 \mathrm{~m}$ in height due to the harsh climate conditions, insufficient soil depth and specific geologic setting (volcanic ashes). This paper presents the study of the vegetation conditions in Iceland using the calculated Landsat TM spectral bands by the QGIS used for computing several VIs using raster 
calculator options. The results present a series of maps showing simulated models using the Landsat TM scene with a coverage of the northern Iceland.

\section{Material and Methods}

The Vls are important indicator of vegetation health, and their calculation requires the use of modern cartographic measuring techniques [1516]. While the most well-known VI often used in the studies is the NDVI, this study presents the comparison of various VIs computed using different band combinations.

Normalized Difference Vegetation Index (NDVI)

The computing of the Normalized Difference Vegetation Index (NDVI) (Figure 2) was done using the expression of the Equation (1)

$$
N D V I=\frac{(N I R-R)}{(N I R+R)}
$$

where NIR is a near infra red, and $R$ is red spectral bands of the Landsat TM. Initially introduced by [17], the NDVI is widely used in the existing literature [18-20] and can be referenced as a graphical indicator to analyse remote sensing scene, if the study area is being covered by live green vegetation.

Ratio Vegetation Index (RVI)

The computing of the Ratio Vegetation Index (RVI) proposed by [21] (Figure 3) was done using the Equation (2)

$$
R V I=\frac{R}{N I R}
$$

where NIR is a near infra red, and $R$ is red spectral band of the Landsat TM, that is, the reflectance in the NIR band divided by the reflectance in the red band. Specifically, the RVI shows the values high for vegetation and low for other land cover types (soil, ice, water). The RVI indicates the amount of vegetation. Its advantage consists in the reduction of the effects of atmosphere and topography.

Normalized Ratio Vegetation Index (NRVI)

The computing of the Normalized Ratio Vegetation Index (NRVI) (Figure 4) was based on the previously computed RVI using the Equation (3):

$$
N R V I=\frac{(R V I-1)}{(R V I+1)}
$$

where RVI is a previously calculated Ratio Vegetation Index. Applying the mathematical corrections for adjustments of spectral data distributions to the previously made RVI enables the NRVI to better distinguish vegetation from soil and perform in a more regular way.
Transformed Vegetation Index (TVI)

The computing of the Transformed Vegetation Index (TVI) (Figure 5) was done using the Equation (4):

$T V I=\sqrt{\left[\frac{(N I R-R)}{(N I R+R)}+0.5\right]}$

(Equation 4)

where NIR is a near infra red, and $R$ is red spectral band of the Landsat TM. This index is derived from a square root of the algebraic expression of NIR and R. The TVI shows the sensitivity of SAVI to the optical proprieties of upper soil layer. In contrast to NDVI and SAVI, it does not saturate and shows better linearity as a function of the rate of vegetation cover [22].

Corrected Transformed Vegetation Index (CTVI) The computing of the Corrected Transformed Vegetation Index (CTVI) (Figure 6) was done using the Equation (5):

$$
C T V I=\frac{(N D V I+0.5)}{(|(N D V I+0.5)|)} * \sqrt{(|(N D V I+0.5)|)}
$$

(Equation 5)

where the NDVI is a previously calculated index according to the Equation (1).

Thiam's Transformed Vegetation Index (TTVI)

The computing of the Thiam's Transformed Vegetation Index (TTVI), proposed by Thiam [23] (Figure 7), was done using the Equation (6):

$$
T T V I=\sqrt{(|(N D V I)|+0.5)}
$$

where the NDVI is a previously calculated index according to the Equation (1).

Soil Adjusted Vegetation Index (SAVI)

The computing of the Soil Adjusted Vegetation Index (SAVI) (Figure 8) was performed using the Equation (7):

$$
S A V I=\frac{(N I R-R)}{(N I R+R)} *(1+S)
$$

where NIR is a near infrared spectrum, $R$ is a red spectrum, $\mathrm{S}$ is a soil adjustment factor, aimed to adjust the NDVI for the influence of soil brightness in areas with low vegetative coverage. More specifically, SAVI minimizes the effects of the soil background on vegetation. To achieve this, the NDVI formula was adjusted by a constant soil factor which varies with the colour and brightness of the soil as its reflectance characteristics [24].

\section{Results and Discussion}

The NDVI (Figure 2) shows values in a range 0.91 to 0.65 . The glacial areas and ice-covered lakes have the lowest values (coloured as crimson brown in Figure 2). Here the NDVI calculates the amount of vegetation by quantifying the difference 
between the NIR which is strongly reflected by vegetation and $\mathrm{R}$, which, in contrast, is absorbed by vegetation, using the formula of NDVI provided in the Methodology section.

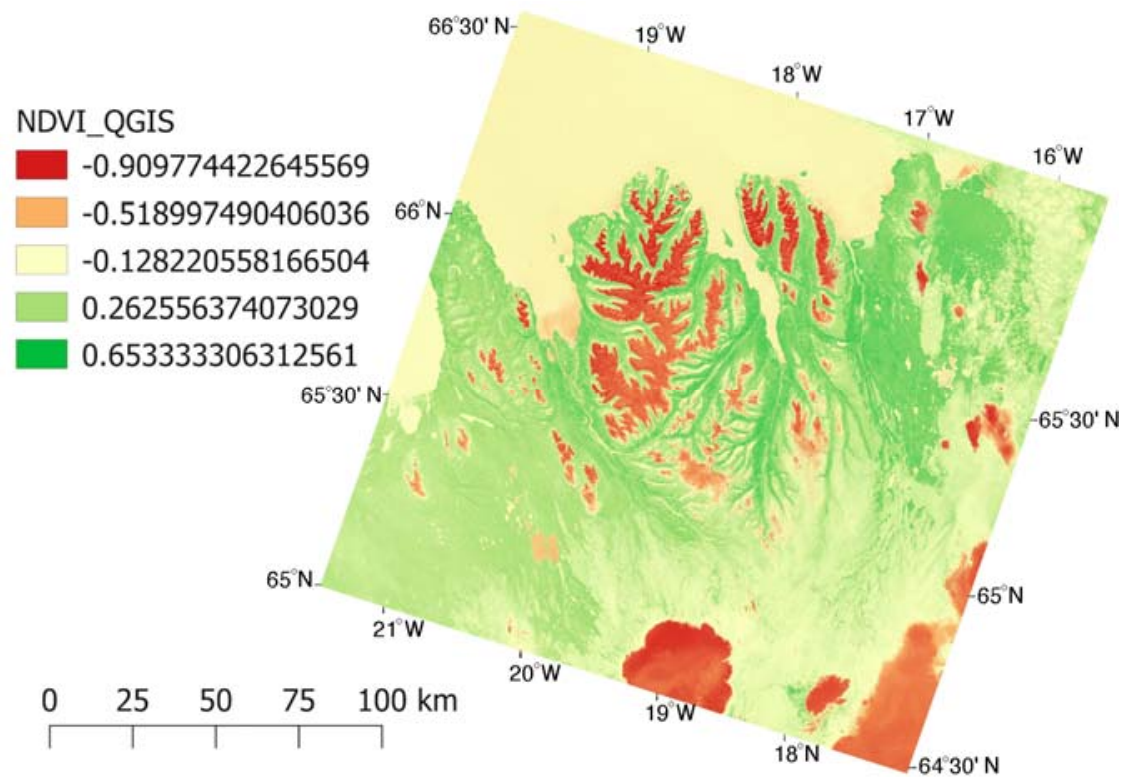

Figure 2. Normalized Difference Vegetation Index (NDVI). Mapping: QGIS. Source: author.

The water areas in fjords show value -0.13 . Similar to the NDVI, the RVI is based on the contrasting values between the red and NIR bands of the Landsat TM image. The RVI (Figure 3) assesses the image in positive values with a range from 0.22 to 19.65 . The dominating values for the glacial areas and lakes are 2.69 (beige colour in Figure 3). The water areas in fjords show value 1.99. The clear difference between the NDVI and RVI indices can be explained by the contrast between the $\mathrm{R}$ and NIR bands for vegetation in both indices. In case of RVI, high index values are induced by the combinations of reflectance values: low $\mathrm{R}$ (chlorophyll) and high NIR (leaf structure).

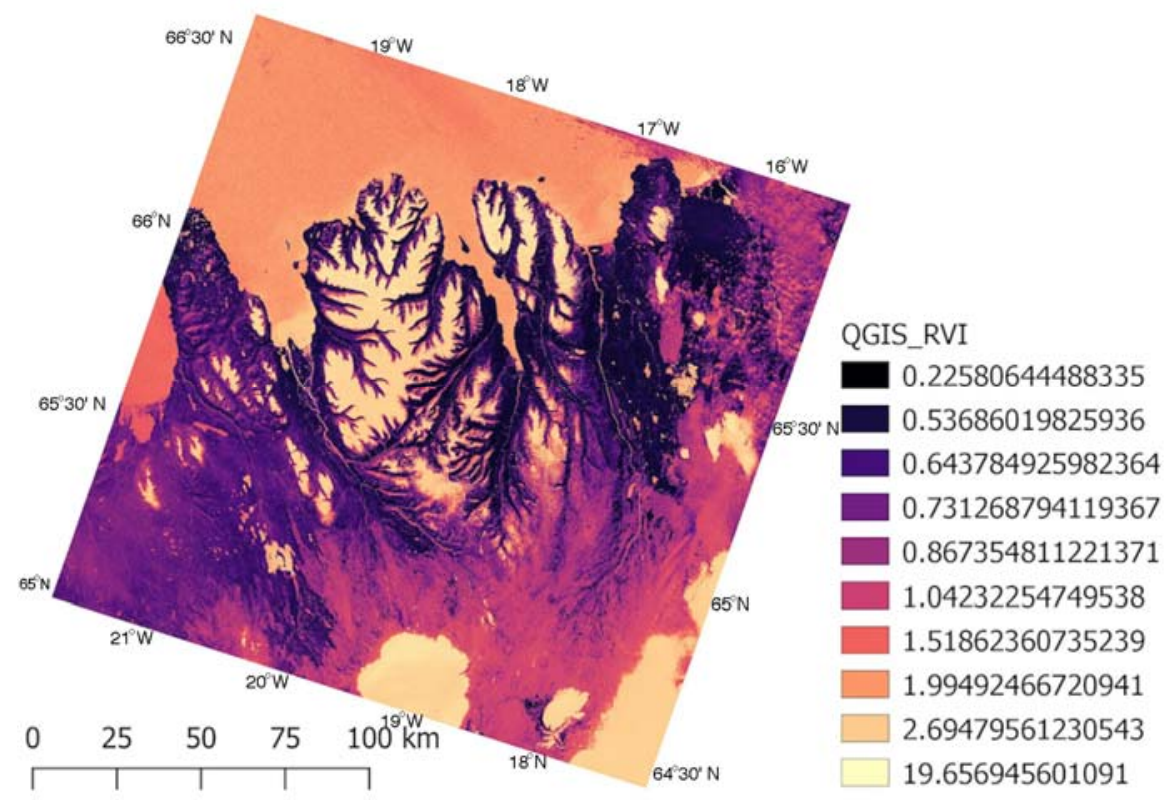

Figure 3. Ratio Vegetation Index (RVI). Mapping: QGIS. Source: author. 
The NRVI is based on the RVI, but NRVI better distinguishes vegetation from soil by a more regular equation. The results of the NRVI calculations (Figure 4) show data variations between the -0.63 to 0.90 . The difference between the RVI and the NRVI can be explained by the technical approach where the result of the expression (RVI - 1) are normalized over the expression (RVI + 1). As a result, such a normalization minimizes the topographic, luminosity and atmospheric effects, creates a statistically normal distribution and performs better comparing to the non-normalized RVI.

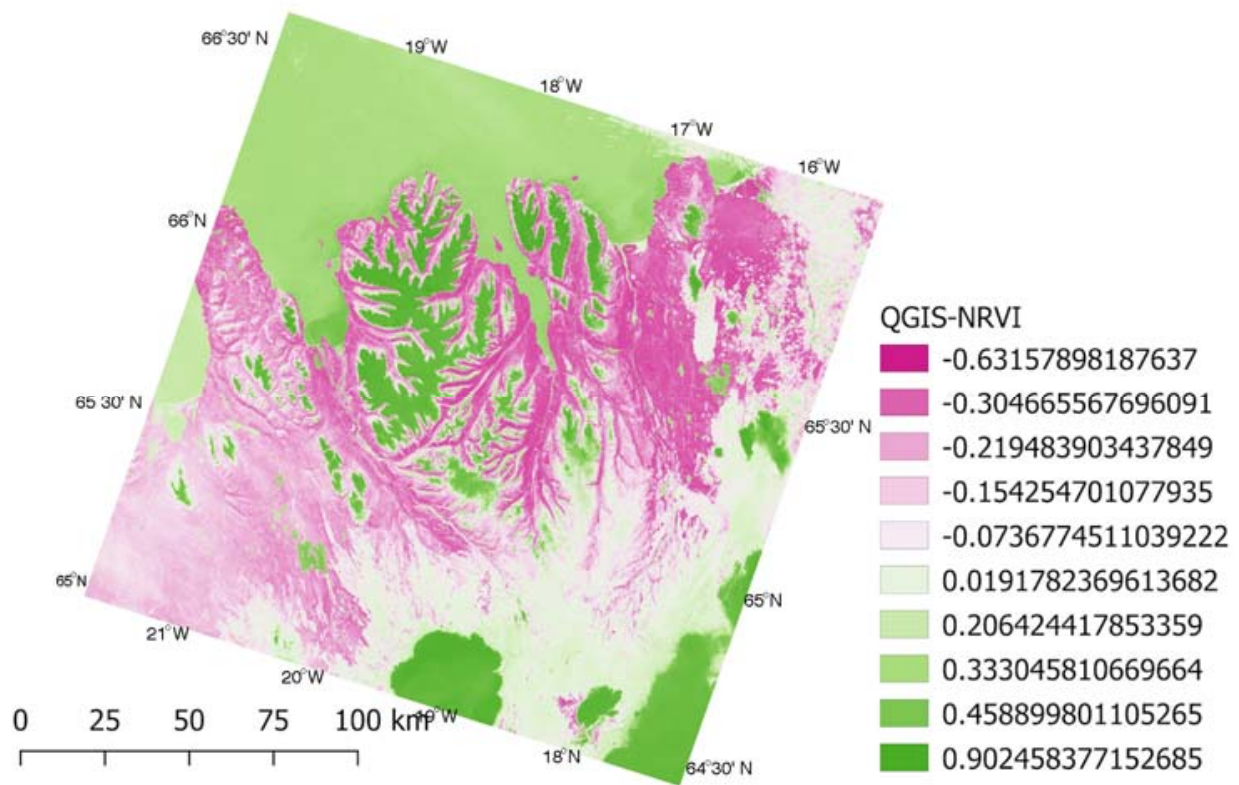

Figure 4. Normalized Ration Vegetation Index (NRVI). Mapping: QGIS. Source: author.

The results of the TVI calculations (Figure 5) show the data range in a dataset from 0 to 1.12, that is, the data are positive according to the embedded methodology of the TVI: the TVI changes the initial NDVI by adding a 0.5 to all its values.
In such a way, this constant enables to avoid operating with negative NDVI values which can eventually be better for the cartographic output (Figure 5).

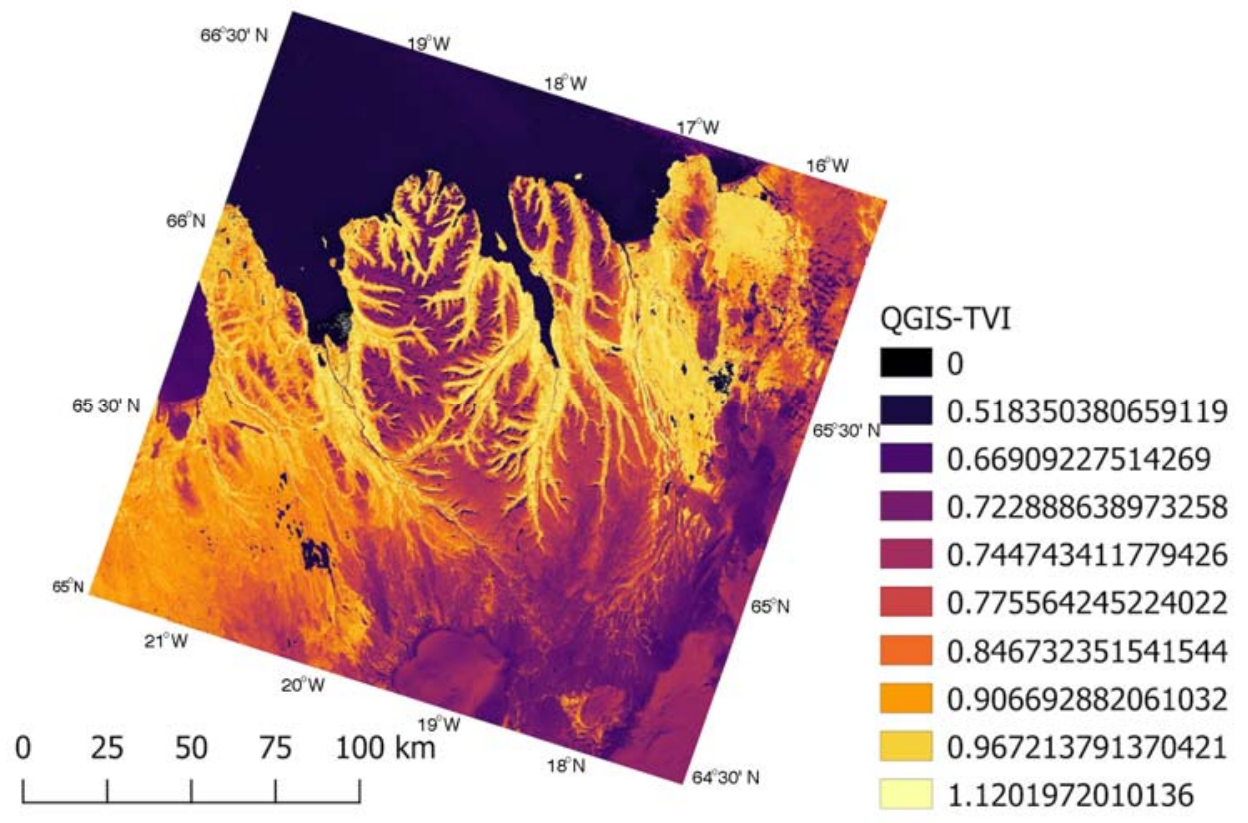

Figure 5. Transformed Vegetation Index (TVI). Mapping: QGIS. Source: author. 
The areas of the significant increase of the TVI trends to correlate with the areas of dense forests, as well as other types of vegetation around the mountains, in the river valleys and fields. Although the TVI decreased in the sea water areas (up to zero) and the areas of inner lakes (0.518 to 0.669 ), there was an increasing TVI trend in the coastal areas and river valleys (to 0.96-1.12 with bright yellow colours). In areas of mountains and persistent land cover, the TVI values were lower (categories 0.74 to 0.77 and 0.77 to 0.84 ) than in mixed land cover types (0.84 to 0.90).

The results of the CTVI calculations (Figure 6) show the dataset range between the -0.64 to 1.07 . So, adding a constant of 0.5 to all the initial NDVI values did not enable to disable negative values in a CTVI (Figure 6), because the initial NDVI values also had negative values up to -0.91 (comparing to Figure 2). The results of the TTVI calculations (Figure 7) show values from 0.70 to 1.18.

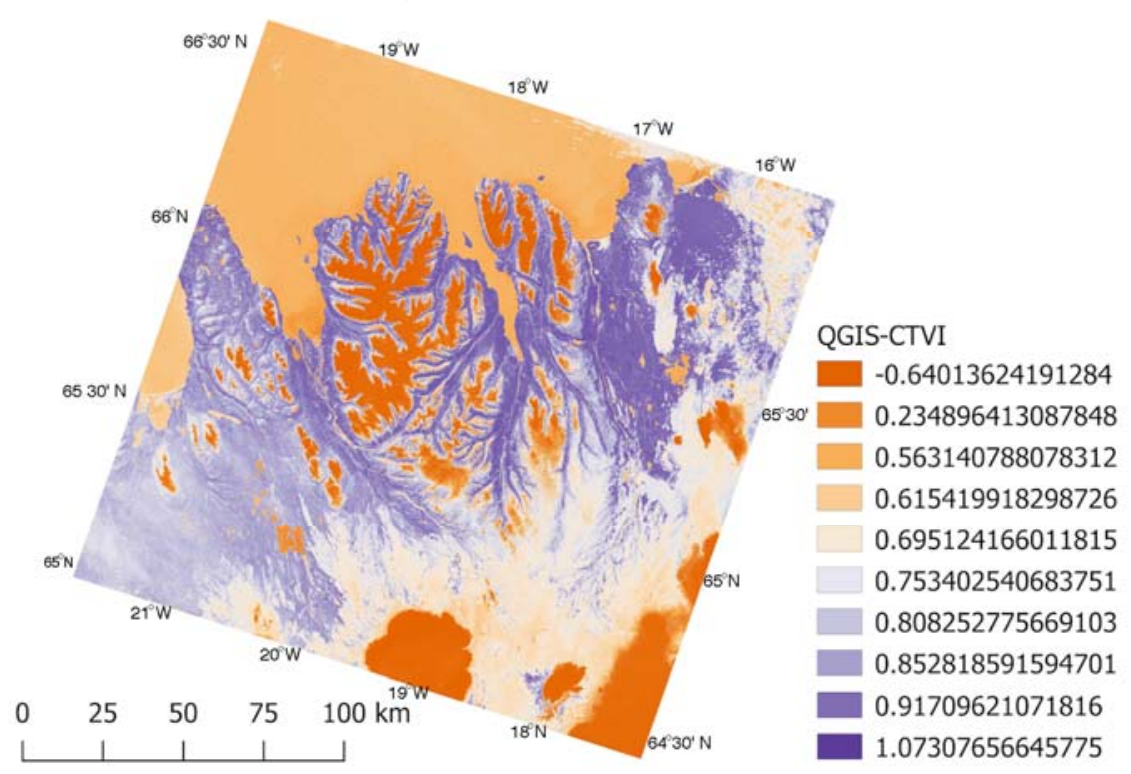

Figure 6. Corrected Transformed Ratio Vegetation Index (CTVI). Mapping: QGIS. Source: author.

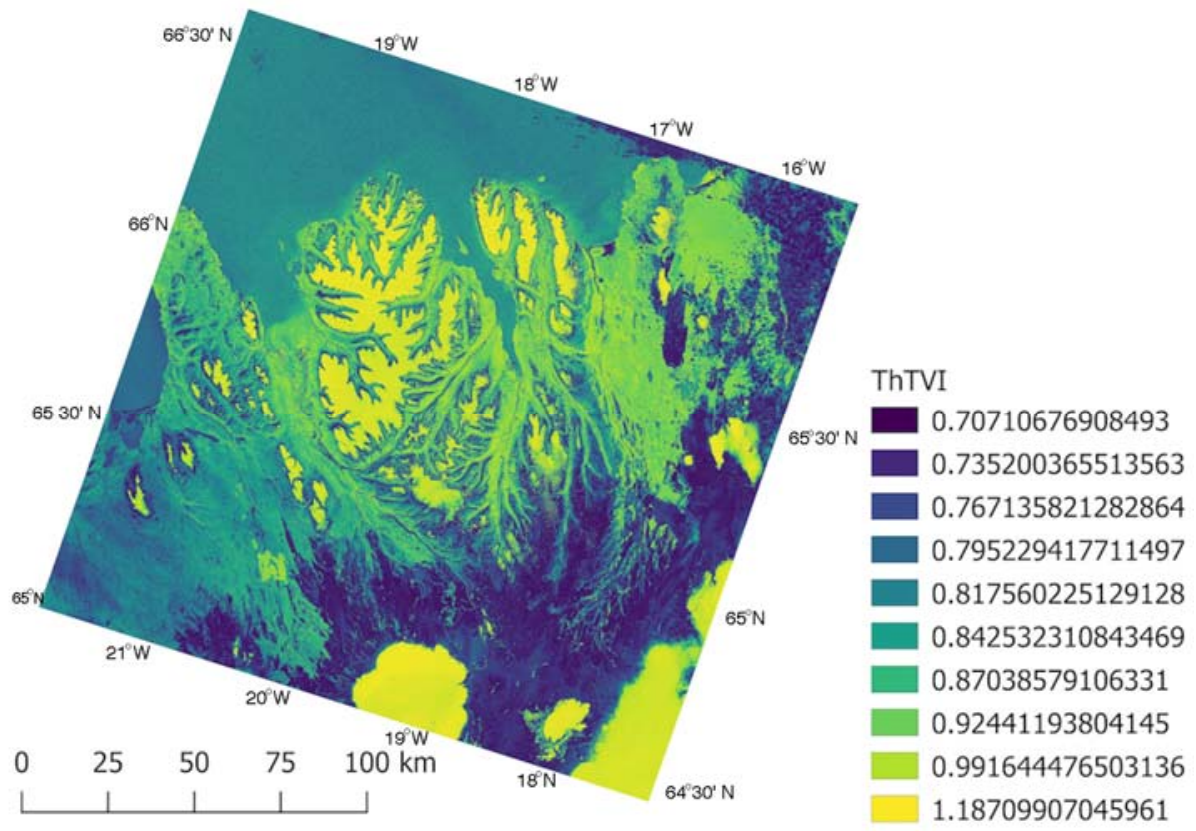

Figure 7. Thiam's Transformed Vegetation Index (TTVI). Mapping: QGIS. Source: author. 


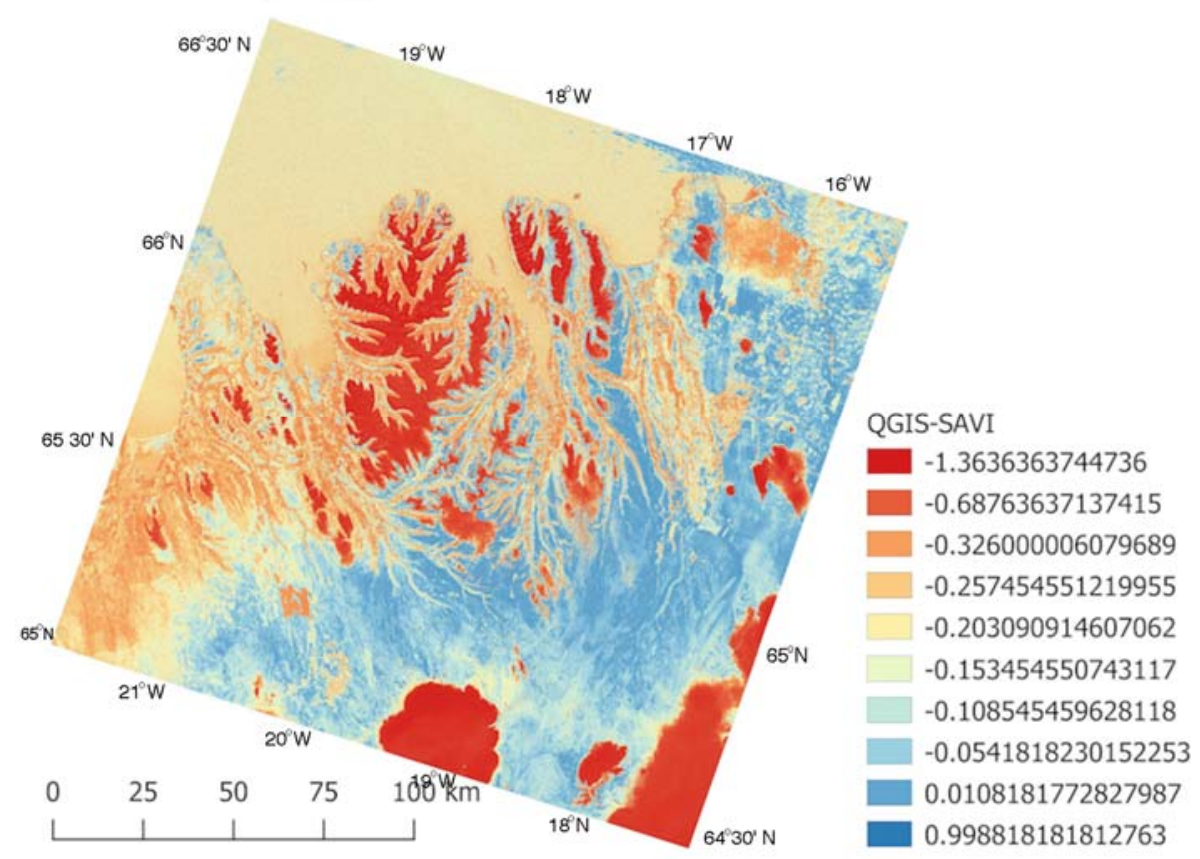

Figure 8. Soil Adjusted Vegetation Index (SAVI). Mapping: QGIS. Source: author.

The results of the SAVI calculations (Figure 8) show the dataset ranging between the -1.36 to 0.99 (roughly to 1.00 ). Such a different data range can be explained by the specifics of the algorithm: the soil adjustment factor depends on the density of the vegetation, therefore, the higher the density, the higher is the actual values (Figure 8). The applicability of the presented methodology of raster calculator in a QGIS and the open source availability of the Landsat TM scenes enables the computing of the VIs in other geographic areas and repeatability of the presented research. However, different environmental components can limit the effectiveness of the VIs and substantiate the choice depending on the geographic conditions of the study area.

The choice of the presented VIs is motivated by the study aim and general geographic setting of the region of the northern coasts of Iceland. All the reviewed VIs are slope-based, which present the clear computed results comparing to the distance-based VIs.

\section{Conclusions}

The research presented the QGIS applicability in the environmental monitoring, which is also applied in previous research in combination with the advanced methods of data analysis [25-26]. In particular, the visualization of various VIs by the Landsat TM has been presented. A Landsat TM image representing various vegetation conditions (mountainous ice-covered, sandy and rocky terrain, forests, coastal areas) covering northern region of Iceland was processed to test the seven slope-based VIs: NDVI, RVI, NRVI, TVI, CTVI, TTVI and SAVI. These spectral VIs were compared for variations in their sensitivity to vegetation conditions. In general, the presented VIs demonstrated a numerical correlation to vegetation distribution and areas.

There were some differences among the VIs over the rocky areas, grassland, and selected forested regions. The application of the machine learning in cartography are diverse and may include automatization in data processing, application of various modules of GIS for cartographic mapping, or using programming languages [27-30]. For the case of remote sensing data processing, automatization include, among other, streaming of the data capture and machine learning in algorithms of raster bands combinations. The presented research demonstrated how the Landsat TM data can be processed and visualized using spectral characteristics of the vegetation.

Apart from the traditionally used software for the raster data processing, such as Erdas Imagine, ENVI GIS, Idrisi GIS, SAGA GIS, the QGIS shows capabilities in the satellite images processing that can be applied in a similar research. Technically, the results demonstrated that cartographic data processing by QGIS is effective for remote 
sensing data processing with an example of the Landsat TM scene.

The visualization of various VIs can be a good estimator for mapping canopy health and botanical studies, especially for regions with harsh climate conditions, such as Iceland. Cartographic data processing by the open source QGIS contribute greatly to the thematic mapping of global vegetation, demonstrating plant growth and health conditions. The demonstrated methodology can be applied for similar studies aimed at the environmental forest monitoring.

\section{References}

1. QGIS.org (2020). QGIS Geographic Information System. Open Source Geospatial Foundation Project. http://qgis.org

2. Bhandari, A. K., Kumar, A., Singh, G. K. (2012). Feature Extraction using Normalized Difference Vegetation Index (NDVI): a Case Study of Jabalpur City. Procedia Technology, 6, 612-621.

3. Gim, H.-J., Ho, C.-H., Jeong, S., Kim J., Feng, S., Hayes, M.J. (2020). Improved mapping and change detection of the start of the crop growing season in the US Corn Belt from long-term AVHRR NDVI. Agricultural and Forest Meteorology, 294, 108143. DOI: 10.1016/j.agrformet.2020.108143

4. Lemenkova, P. (2016). Using GIS for Monitoring Lacustrine Ecosystem: a Case Study of Laguna de Gallocanta, Spain. Problems of the Environmental Landscape Planning, 237-240.

5. Lemenkova, P. (2015). Modelling Landscape Changes and Detecting Land Cover Types by Means of the Remote Sensing Data and ILWIS GIS". Information Technologies. Problems and Solutions, 265-271.

6. French, A. N., Hunsaker, D. J., Sanchez, C. A., Saber, M., Gonzalez, J. R., Anderson, R. (2020). Satellite-based NDVI crop coefficients and evapotranspiration with eddy covariance validation for multiple durum wheat fields in the US Southwest. Agricultural Water Management, 239, 106266.

7. Lemenkova, P. (2011). Seagrass Mapping and Monitoring Along the Coasts of Crete, Greece. M.Sc. Thesis. University of Twente, Faculty of Earth Observation and Geoinformation (ITC), Enschede, Netherlands.

8. Eddudóttir, S.D., Erlendsson, E., Gísladóttir, G. (2015). Life on the periphery is tough: vegetation in Northwest Iceland and its responses to early-Holocene warmth and later climate fluctuations. Holocene, 25, 1437-1453.

9. Etzelmüller, B., Patton, H., Schomacker, A., Czekirda, J., Girod, L., Hubbard, A., Lilleøren, K.S., Westermann, S. (2020). Icelandic permafrost dynamics since the Last Glacial Maximum - model results and geomorphological implications. Quaternary Science Review, 233, 106236.

10. Cabedo-Sanz, P., Belt, S.T., Jennings, A.E., Andrews, J.T., Geirsdottir, A. (2016). Variability in drift ice export from the Arctic Ocean to the North Icelandic Shelf over the last 8000 years: a multi-proxy evaluation. Quaternary Science Reviews, 146, 99-115.
11. Arnalds, O. (2001). Soil Erosion in Iceland. Agricultural Research Institute, Soil Conservation Service, Reykjavík.

12. Eddudóttir, S.D., Erlendsson, E., Tinganelli, L., Gísladottir, G. (2016). Climate change and human impact in a sensitive ecosystem: the Holocene environment of the Northwest Icelandic highland margin. Boreas, 45, 715-728.

13. Kardjilov, M., Gisladottir, G., Gislason, S. (2006). Land degradation in northeastern Iceland: present and past carbon fluxes. Land Degradation \& Development, 17, 401-417.

14. Petursdottir, T., Baker, S., Aradottir, A.L. (2020). Functional silos and other governance challenges of rangeland management in Iceland. Environmental Science \& Policy, 105, 37-46.

15. du Plessis, W.P. (1999). Linear regression relationships between $\mathrm{NDVI}$, vegetation and rainfall in Etosha National Park, Namibia. Journal of Arid Environments, 42, 235-260.

16. Gu, Y., Wylie, B.K., Howard, D.M., Phuyal, K.P., Jia, L. (2013). NDVI saturation adjustment: A new approach for improving cropland performance estimates in the Greater Platte River Basin, USA. Ecological Indicators, 30, 1-6.

17. Rouse, J.W. Jr., Haas, R.H., Deering, D.W., Schell, J.A., Harlan, J.C. (1974). Monitoring the Vernal Advancement and Retrogradation (Green Wave Effect) of Natural Vegetation. NASA/GSFC Type III Final Report, Greenbelt, MD., 371p.

18. Burgess, D. W., Lewis, P., Muller, J-P.A.L. (1995). Topographic Effects in AVHRR NDVI Data. Remote Sensing of Environment, 54, 223-232.

19. Lemenkova, P. (2015). Analysis of Landsat NDVI Time Series for Detecting Degradation of Vegetation. In: Geoecology and Sustainable Use of Mineral Resources. From Science to Practice, Belgorod, Russia, 11-13.

20. Lemenkova, P. (2014). Detection of Vegetation Coverage in Urban Agglomeration of Brussels by NDVI Indicator Using eCognition Software and Remote Sensing Measurements. In: GIS and Remote Sensing. November 17-19, 2014, Tsaghkadzor, Armenia, 112119.

21. Richardson, A.J., Wiegand, C.L. (1977). Distinguishing Vegetation From Soil Background Information. Photogramnetric Engineering and Remote Sensing, 43(12), 1541-1552.

22. Bannari, A., Asalhi, H., Teillet, P.M. (2002). Transformed Difference Vegetation Index (TDVI) for Vegetation Cover Mapping. IEEE Xplore Conf. Proc., 3053-3055.

23. Thiam, A.K. (1997). Geographic Information Systems and Remote Sensing Methods for Assessing and Monitoring Land Degradation in the Sahel: The Case of Southern Mauritania. PhD Thesis. Clark University, Worcester Massachusetts.

24. Huete, A.R. (1988). A Soil-Adjusted Vegetation Index (SAVI). Remote Sensing of Environment, 25(3): 295-309.

25. Lemenkova, P. (2019). Statistical Analysis of the Mariana Trench Geomorphology Using R Programming Language. Geodesy and Cartography, 45(2), 57-84. 
26. Lemenkova, P. (2019). Processing oceanographic data by Python libraries NumPy, SciPy and Pandas. Aquatic Research, 2(2), 73-91.

27. Schenke, H. W., Lemenkova, P. (2008). Zur Frage der Meeresboden-Kartographie: Die Nutzung von AutoTrace Digitizer für die Vektorisierung der Bathymetrischen Daten in der Petschora-See. Hydrographische Nachrichten, 81, 16-21.

28. Suetova, I. A., Ushakova, L. A., Lemenkova, P. (2005). Geoinformation mapping of the Barents and
Pechora Seas. Geography and Natural Resources, 4, 138-142.

29. Lemenkova, P. (2019). AWK and GNU Octave Programming Languages Integrated with Generic Mapping Tools for Geomorphological Analysis. GeoScience Engineering, 65 (4), 1-22.

30. Klaučo, M., Gregorová, B., Stankov, U., Marković, V., Lemenkova, P. (2013). Determination of ecological significance based on geostatistical assessment: a case study from the Slovak Natura 2000 protected area. Open Geosciences, 5(1), 28-42. 